An Osmotic Membrane Bioreactor - Membrane Distillation System for Simultaneous Wastewater Reuse and Seawater Desalination: Performance and Implications

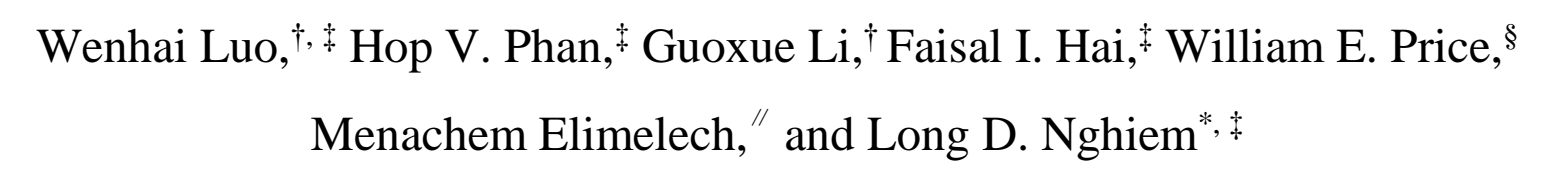

${ }^{\dagger}$ Beijing Key Laboratory of Farmland Soil Pollution Prevention and Remediation, College of Resources and Environmental Sciences, China Agricultural University, Beijing, 100193, China

$\star$ Strategic Water Infrastructure Laboratory, School of Civil, Mining and Environmental Engineering, University of Wollongong, Wollongong, NSW 2522, Australia
${ }^{\S}$ Strategic Water Infrastructure Laboratory, School of Chemistry, University of Wollongong, Wollongong, NSW 2522, Australia
"Department of Chemical and Environmental Engineering, Yale University, New Haven, Connecticut 06520-8286, United States

* Corresponding author: longn@uow.edu.au; Ph: +61 (2) 42214590. 
18 In this study, we demonstrate the potential of an osmotic membrane bioreactor (OMBR) membrane distillation (MD) hybrid system for simultaneous wastewater reuse and seawater desalination. A stable OMBR water flux of approximately $6 \mathrm{~L} \mathrm{~m}^{-2} \mathrm{~h}^{-1}$ was achieved when using

21 MD to regenerate the seawater draw solution. Water production by the MD process was higher

22 than that from OMBR to desalinate additional seawater and thus account for draw solute loss due to the reverse salt flux. Amplicon sequencing on the Miseq Illumina platform evidenced bacterial acclimatization to salinity build-up in the bioreactor, though there was a reduction in the bacterial community diversity. In particular, 18 halophilic and halotolerant bacterial genera were identified with notable abundance in the bioreactor. Thus, the effective biological treatment was maintained during OMBR-MD operation. By coupling biological treatment and two high rejection membrane processes, the OMBR-MD hybrid system could effectively remove (> 90\%) all 30 trace organic contaminants of significant concern investigated here and produce high quality water. Nevertheless, further study is necessary to address MD membrane fouling due to

31 the accumulation of organic matter, particularly protein- and humic-like substances, in seawater draw solution.

\section{TOC Art}

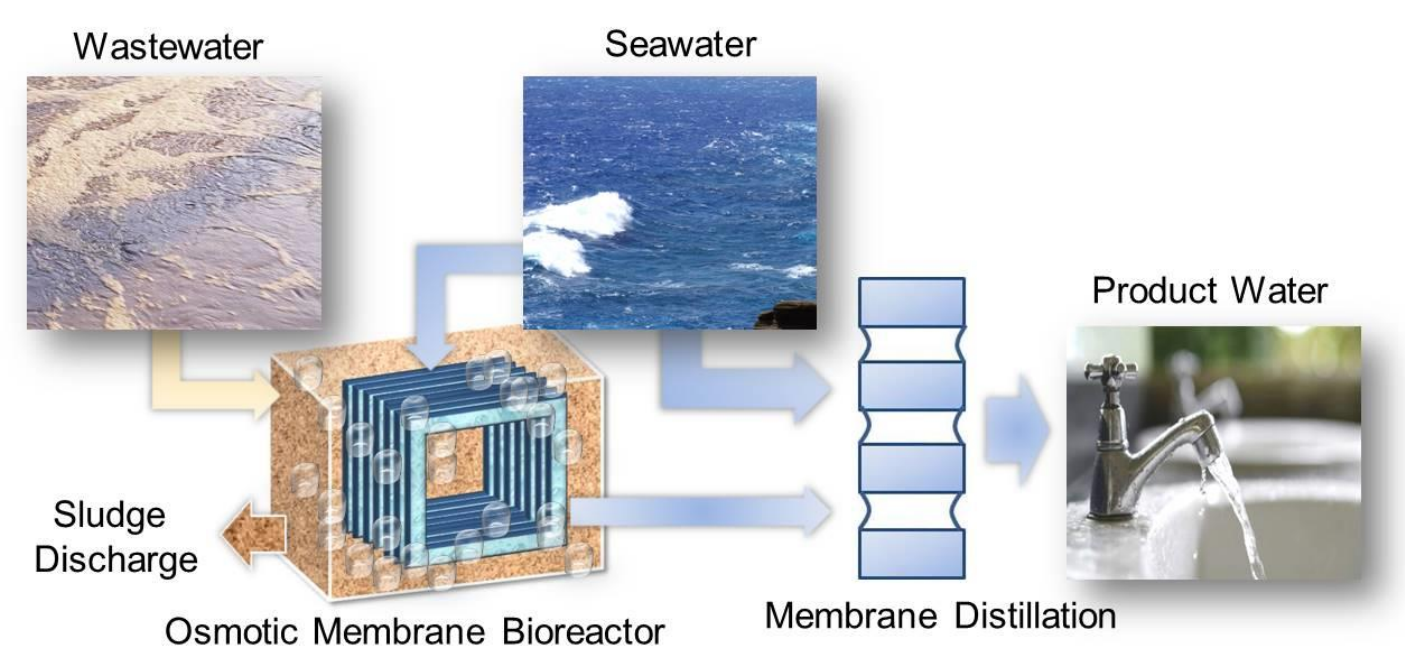


Wastewater reuse and seawater desalination are reliable and pragmatic options to augment water supply. ${ }^{1-3}$ Wastewater effluent reuse is also a cost-effective approach for environmental protection. ${ }^{2}$ Therefore, significant efforts have been dedicated to develop new as well as to improve existing technologies for wastewater reuse and seawater desalination.

Osmotic membrane bioreactor (OMBR), which integrates forward osmosis (FO) with a biological treatment process, has recently been proposed for advanced wastewater treatment and reuse. $^{4-8}$ In OMBR, water is transported from the mixed liquor into a highly concentrated draw solution, with osmotic pressure difference between these two solutions as the driving force. Compared to conventional MBR using either microfiltration or ultrafiltration, OMBR has several advantages, including lower membrane fouling propensity, higher fouling reversibility, and better product water quality. ${ }^{8,9}$ There is also evidence that OMBR can increase the removal of trace organic contaminants (TrOCs) of significant concern, especially biologically persistent compounds, in comparison with conventional MBR..$^{10}$

Salinity build-up in the bioreactor is an inherent problem associated with OMBR due to the high salt rejection by the FO membrane and the reverse salt flux from the draw solution. ${ }^{8,9}$ Salinity build-up can increase the osmotic pressure in the mixed liquor side and thus reduce the effective driving force for water diffusion. More importantly, salinity build-up can alter biomass characteristics and biological community, thereby deteriorating the biological performance of OMBR. ${ }^{11,12}$ It has been recently hypothesized that the bacterial population may acclimatize to the salinity increase by the proliferation of halotolerant or halophilic bacteria. ${ }^{10,13}$ However, to date, this hypothesis has not been systematically evaluated and verified.

For water reuse applications, an additional process, such as reverse osmosis (RO) or membrane distillation (MD), can be integrated with OMBR to regenerate the draw solution and produce clean water. Recent studies have demonstrated the robust performance of the OMBRRO hybrid system for wastewater treatment and reuse. ${ }^{10,14-16}$ Compared to conventional MBRRO, OMBR can prevent the downstream RO process from severe membrane fouling and thus maintain the system sustainability. ${ }^{10} \mathrm{MD}$ is a thermally driven process, where water is transported as vapor under a partial vapor pressure gradient from a high temperature solution, through a microporous, hydrophobic membrane, to a low temperature solution. MD can 
completely reject non-volatile substances. ${ }^{17}$ In addition, MD performance is not significantly affected by the feed water salinity, rendering it as a promising process for the desalination of highly saline streams. ${ }^{18}$ As a result, MD is potentially viable to regenerate draw solutions for OMBR.

Little is known about the performance of the OMBR-MD hybrid system for wastewater treatment and reuse. Nguyen et al. ${ }^{19}, 20$ reported that the MD process could successfully regenerate the diluted draw solution within six hours of batch operation when integrated with either attached growth biofilm-OMBR or sponge biocarrier-OMBR. Shahzad et al. ${ }^{21}$ subsequently optimized the MD process to continuously recover diluted draw solutions for OMBR. However, MD and OMBR experiments were conducted separately and the performance of the OMBR-MD hybrid system was not evaluated in these studies.

OMBR integrated with either RO or MD can potentially be deployed for simultaneous wastewater reuse and seawater desalination. This concept is inspired by recently reported FORO systems using seawater as the draw solution. In these systems, the FO process was used to purify impaired water for seawater dilution, thereby increasing the water recovery and reducing the specific energy consumption of seawater desalination by the RO process. ${ }^{22-25}$ Nevertheless, there has been very little research work on the performance of OMBR using seawater as the draw solution. Compared to RO, MD performance is not affected by the feed osmotic pressure and thus can be a better option to integrate with OMBR for simultaneous wastewater reuse and seawater desalination, particularly when waste heat or solar energy is readily available.

In this study, we investigate the overall performance of an OMBR-MD hybrid system for simultaneous wastewater reuse and seawater desalination. The performance was systematically assessed in terms of water production, contaminant removal, and membrane fouling. Removal mechanisms of TrOCs in the hybrid system were elucidated. In addition, 16S rRNA gene sequencing on the MiSeq Illumina platform was performed to reveal the evolution of the bacterial community in the bioreactor during OMBR-MD operation.

\section{MATERIALS AND METHODS}

Wastewater and Seawater. A synthetic wastewater solution was used in this study to avoid the interference of indigenous microbes from real wastewater in investigating the evolution of the bacterial community with salinity build-up in the bioreactor. The synthetic wastewater was 
prepared daily to obtain $100 \mathrm{mg} / \mathrm{L}$ glucose, $100 \mathrm{mg} / \mathrm{L}$ peptone, $17.5 \mathrm{mg} / \mathrm{L} \mathrm{KH}_{2} \mathrm{PO}_{4}, 17.5 \mathrm{mg} / \mathrm{L}$ $\mathrm{MgSO}_{4}, 17.5 \mathrm{mg} / \mathrm{L} \mathrm{CaCl}_{2}, 10 \mathrm{mg} / \mathrm{L} \mathrm{FeSO}_{4}, 225 \mathrm{mg} / \mathrm{L} \mathrm{CH} \mathrm{CH}_{3} \mathrm{COONa}$, and $35 \mathrm{mg} / \mathrm{L}$ urea to represent moderate strength municipal wastewater. Seawater was collected from Wollongong beach (New South Wales, Australia) and filtered through $0.45 \mu \mathrm{m}$ filter papers before using as the draw solution in the OMBR-MD system. Key physicochemical properties of the synthetic wastewater and seawater are summarized in Table S1 of the Supporting Information (SI).

FO and MD Membranes. A flat-sheet, thin-film composite FO membrane from Hydration Technology Innovations (Albany, OR) was used in OMBR. The FO membrane consisted of a thin, selective polyamide active layer on top of a porous polysulfone supporting layer. A microporous, hydrophobic membrane from Porous Membrane Technology (Ningbo, China) was used for MD. The MD membrane was composed of a thin polytetrafluorethylene (PTFE) active layer and a polypropylene supporting layer. Key properties of the FO and MD membranes are given in Table $\mathrm{S} 2$ of the SI.

Trace Organic Contaminants (TrOCs). A stock solution containing $25 \mu \mathrm{g} / \mathrm{mL}$ of each of 30 TrOCs was prepared in pure methanol and stored at $-18^{\circ} \mathrm{C}$ in the dark. These 30 compounds were selected to represent chemicals of emerging concern that occur ubiquitously in municipal wastewater. ${ }^{26}$ The stock solution was introduced daily into the synthetic wastewater to achieve a concentration of $5 \mu \mathrm{g} / \mathrm{L}$ of each compound. Key physicochemical properties of the 30 compounds are summarized in Table S3 of the SI. Based on their Log $D$ values (i.e., effective octanol-water partition coefficient) at solution $\mathrm{pH}$, the 30 TrOCs could be grouped as hydrophilic $(\log D<3.2)$ and hydrophobic $(\log D>3.2) .{ }^{27}$

OMBR-MD System. The lab-scale OMBR-MD hybrid system used in this study consisted of a glass bioreactor, a submerged, plate-and-frame FO membrane cell, a direct contact MD (DCMD) membrane cell, feeding and circulating pumps, solution reservoirs, and temperature control equipment (Figure 1). A Masterflex peristaltic pump (Cole-Parmer, Vernon Hills, IL) controlled by a water level sensor was used to feed wastewater into the bioreactor. A wastewater reservoir was placed on a digital balance (Mettler-Toledo, Hightstown, IL), which was connected with a computer to determine the OMBR water flux. The bioreactor was placed in a water bath to maintain the mixed liquor temperature at $25 \pm 1{ }^{\circ} \mathrm{C}$ using a temperature controller (Neslab RTE7, Waltham, MA) equipped with a stainless steel heat exchanger coil (Figure S1, SI). 
The FO membrane cell was made of acrylic plastic. A draw solution channel was engraved in the acrylic block with a length, width, and depth of 20, 15, and $0.4 \mathrm{~cm}$, respectively. The FO membrane with an effective area of $300 \mathrm{~cm}^{2}$ was mounted on the cell with the supporting layer in contact with the draw solution (i.e., FO mode). A gear pump (Micropump, Vancouver, WA) was used to circulate seawater from a stainless steel reservoir to the membrane cell at a crossflow velocity of $2.8 \mathrm{~cm} / \mathrm{s}$.

The MD membrane cell was also made of acrylic plastic to minimize heat loss and consisted of two identical semi-cells engraved for the feed and distillate channels. Each channel was 14.2 cm long, $9.1 \mathrm{~cm}$ wide, and $0.3 \mathrm{~cm}$ deep. A diamond-patterned, polypropylene (PP) spacer (1.65 mm spacer, GE Osmonics) was placed in each semi-cell. Two gear pumps (Micropump, Vancouver, WA) were used to circulate co-currently the feed (i.e., seawater) and distillate to the membrane cell at a cross-flow velocity of $6.1 \mathrm{~cm} / \mathrm{s}$. Seawater fed to MD was heated to $40 \pm 1{ }^{\circ} \mathrm{C}$ in a stainless steel heat exchanger coil using a proportional-integral-derivative regulator heater (Neslab RTE7, Thermo Scientific, USA). Another temperature controller (Neslab RTE7, Waltham, MA) was used to maintain the distillate temperature at $20 \pm 1{ }^{\circ} \mathrm{C}$. A digital balance connected to a computer was used to weigh excess distillate to determine the MD water flux. Since the water production of MD was independent of that of OMBR, an additional seawater reservoir controlled by a float valve was set to maintain the working volume of the draw solution at $10 \mathrm{~L}$.

Experimental Protocol. The OMBR-MD hybrid system was continuously operated for 40 days in a temperature-controlled room $\left(22 \pm 1{ }^{\circ} \mathrm{C}\right)$. Activated sludge seeded to OMBR was obtained from a lab-scale MBR, which had been stabilized for over three months. The initial mixed liquor suspended solids (MLSS) concentration was adjusted to approximately $6 \mathrm{~g} / \mathrm{L}$. The bioreactor with a working volume of $5 \mathrm{~L}$ was continuously aerated to achieve dissolved oxygen (DO) concentration of more than $2 \mathrm{mg} / \mathrm{L}$. The sludge retention time (SRT) was maintained at 20 days by periodic sludge withdrawal. The hydraulic retention time (HRT) was determined by the OMBR water flux and was in the range of $30-40$ hours. This HRT range was higher than that of a typical MBR due to the low FO water flux. No membrane cleaning was conducted throughout the experiment. 
Water Quality Analyses. Aqueous samples were collected weekly for TrOC analysis according to a method previously described by Hai et al. ${ }^{28}$ Briefly, this method involved solid phase extraction, derivatization, and quantification by a gas chromatography-mass spectrometry system (QP5000, Shimadzu, Kyoto). TrOC removals by biological treatment, OMBR, and the OMBR-MD hybrid system were determined based on mass balance (Section S1, SI). Contributions of the FO and MD membranes toward TrOC removal in the hybrid system were quantified by their observed rejections, which were the removal difference between bioreactor and OMBR, and that between OMBR and OMBR-MD, respectively (Section S1, SI).

Basic water quality parameters were also measured. Total organic carbon (TOC) and total nitrogen $(\mathrm{TN})$ were detected by a TOC/TN analyzer (TOC-V $\mathrm{V}_{\mathrm{CSH}}$, Shimadzu, Kyoto). Ammonium $\left(\mathrm{NH}_{4}{ }^{+}\right)$and orthophosphate $\left(\mathrm{PO}_{4}{ }^{3-}\right)$ were analyzed by a Flow Injection Analysis system (QuikChem 8500, Lachat, CO). Solution pH and electrical conductivity were monitored by an Orion 4-Star Plus pH/conductivity meter (Thermo Scientific, Waltham, MA).

Microbial Community Analysis. Mixed liquor samples were collected every ten days for microbial analysis based on a method reported by Luo et al. ${ }^{13}$ Briefly, this method included DNA extraction using the FastDNA ${ }^{\circledR}$ SPIN Kit for soil (MP Biomedicals, Santa Ana, CA), PCR amplification of V3 - V4 16S rRNA gene using primer pairs of 341F 5'CCTAYGGGRBGCASCAG-3' and 806R 5'-GGACTACNNGGGTATCTAAT-3', and amplicon sequencing on the Illumina MiSeq platform (Australian Genome Research Facility, Queensland, Australia).

Paired-end reads were assembled using PEAR (version 0.9.8) (9) $^{29}$ and then processed with Quantitative Insights into Microbial Ecology (QIIME 1.9.1) ${ }^{30}$, USEARCH (version 8.0.1623) ${ }^{31}$, and UPARSE pipeline. Taxonomy was assigned by the Ribosomal Database Project (RDP) classifer with the Microbial Database for Activated Sludge (MiDAS) (version 2.1.3) ${ }^{32}$ as the reference. Both $\alpha$-diversity (diversity within communities) and $\beta$-diversity (partitioning of diversity among communities) were determined at the Operational Taxonomic Unit (OTU) level (> 97\% sequence similarity) to examine impacts of salinity build-up on the bacterial community structure and dynamics. Specifically, the $\alpha$-diveristy was indicated by the Chao 1 index, observed OTUs, Shannon index, and phylogenetic diversity. The Chao 1 index is an estimate of the total OTU richness in a community when a saturated number of sequences are collected. ${ }^{33}$ The observed OTUs are the number of unique OTUs that are observed in a given sample, which 
is commonly lower than the Chao 1 index. The Shannon index determines the abundance and evenness of bacterial species in a community. ${ }^{34}$ A higher Shannon index indicates greater bacterial diversity and a more uniform distribution. Phylogenetic diversity represents the phylogenetic relationship based on the sum of the total branch length in a phylogenetic tree that leads to each member of a community. ${ }^{35}$ A higher phylogenetic diversity indicates a more widely distributed bacterial community. The $\beta$-diversity was determined by unweighted UniFrac distance metrics that was interpreted via the principal coordinate analysis (PCoA) and unweighted pair group method with arithmetic mean. ${ }^{13}$ All sequencing data in this study are available at the Sequence Read Archive (Accession Number: SRP096094) in the National Center for Biotechnology Information (Bethesda, MD).

Membrane Hydrophobicity. At the conclusion of OMBR-MD operation, the hydrophobicity of the MD membrane was evaluated by contact angle measurements using a Rame-Hart Goniometer (Model 250, Rame-Hart, Netcong, NJ) based on the standard sessile drop method. Ten water droplets were applied to the membrane sample and contact angles on both sides of the droplet were analyzed.

\section{RESULTS AND DISCUSSION}

Water Flux of OMBR and MD. A stable water flux (approximately $6 \mathrm{~L} \mathrm{~m}^{-2} \mathrm{~h}^{-1}$ ) was achieved during OMBR operation (Figure 2A), despite a notable salinity build-up in the bioreactor (Figure 2B). The observed salinity increase in the bioreactor is mainly attributed to the high salt rejection by the FO membrane. The reverse salt flux from the draw solution is likely to be less significant because of the high selectivity of the TFC FO membrane. ${ }^{36,37}$ During OMBRMD operation, the rate of water extraction from the seawater draw solution by MD was higher than that through the FO process, particularly within the first 20 days (Figure S2, SI). In other words, the draw solution was continuously replenished with additional seawater to compensate draw solute loss due to the reverse salt flux. As a result, the continuous seawater addition caused a proportional increase in the draw solution salinity (Figure 2B), which offsets the build-up of salinity in the bioreactor. This results in a relatively constant osmotic driving force (i.e., transmembrane osmotic pressure) for water diffusion.

\section{[Figure 2]}


formation was observed on the membrane active layer at the end of the experiment. The SEMEDS analysis showed that only a few particles, consisting of carbon, oxygen, sodium, magnesium, phosphorus, and chloride, scattered on the membrane surface (Figure S3A, SI). It is noteworthy that continuous aeration to activated sludge for microbial growth could mitigate FO membrane fouling by generating hydrodynamic turbulence adjacent to the membrane surface. ${ }^{38}$,

${ }^{39}$ A similar fouling pattern was also observed on the membrane supporting layer. Since seawater was pretreated with $0.45 \mu \mathrm{m}$ filter papers before using as the draw solution and the direction of the water flux was outward of the membrane supporting layer, fouling on the FO membrane supporting side was not expected. Only a few solid particles, whose elementary composition matched key elements of seawater, were distributed sparingly on the membrane supporting layer (Figure S3B, SI).

Water flux of the MD process decreased continuously (Figure 2A). The observed flux decline is attributed to membrane fouling due to the deposition of organic matter on the membrane surface (Figure S3C, SI). During OMBR-MD operation, a small but nevertheless discernible accumulation of protein- and humic-like substances in the draw solution was observed (Figure S4, SI). These organic substances induced severe organic fouling of the MD membrane, particularly in the presence of divalent cations (e.g., $\mathrm{Ca}^{2+}$ and $\mathrm{Mg}^{2+}$ ) in seawater serving as foulant bridges. ${ }^{40}$ Fouling of the MD membrane was also indicated by a significant reduction in membrane hydrophobicity. Over the entire OMBR-MD operation, the contact angle of the MD membrane decreased from $135 \pm 10^{\circ}$ (pristine membrane) to $67 \pm 5^{\circ}$. Thus, further research to address the accumulation of organic matter in the draw solution and to control MD membrane fouling is necessary for the sustainable operation of the OMBR-MD hybrid system. quantitatively evaluate microbial responses to salinity build-up in the bioreactor during OMBRMD operation using seawater as the draw solution. Results in Figure 3 show that initial salinity build-up in the bioreactor reduced the bacterial community diversity. Within the first 20 days, $\alpha$ diversity indices (i.e., Chao 1 value, observed OTUs, Shannon index, and phylogenetic diversity) decreased significantly (Figure 3), possibly due to the inhibitory effect of salinity increase on the 
in Figure 3 also show stable $\alpha$-diversity indices from day 20 onward, which can be seen as an evidence of bacterial acclimatization to the saline environment in the bioreactor. Such variation in $\alpha$-diversity was corroborated by PCoA and hierarchical clustering of the unweighted UniFrac distance. Both PCoA and hierarchical clustering show that the bacterial community structure varied mostly within the first 20 days of operation, thereafter, changes in the bacterial community were insignificant (Figure S5, SI). Similar bacterial adaptation to the elevated salinity has been observed, for example, in conventional MBR with continuous increase in feed salinity ${ }^{13}$ and a natural estuary with salinity gradient ${ }^{41}$.

\section{[Figure 3]}

Impacts of salinity build-up in the bioreactor on the bacterial community diversity and structure were further examined by the taxonomic analysis at the genus level (Figures 4 and 5). Based on the MiDAS database, ${ }^{32} 75-90 \%$ of the obtained sequences could be classified at the genus level, mostly belonging to 12 abundant bacterial phyla (Fig. S6, SI). Results from the taxonomic analysis show that the bacterial consortium can be divided into three groups with different responses to salinity build-up in the bioreactor.

In the first group, the growth of microbes was inhibited by salinity build-up in the bioreactor. Given their susceptibility to the saline condition, these bacteria could be considered as halophobic. ${ }^{12}$ Microbial analysis at the genus level show that 18 halophobic bacteria were initially abundant in the bioreactor; however, their abundance decreased significantly with salinity build-up (Figure 4), possibly due to cell plasmolysis under the elevated saline condition. ${ }^{13}$

\section{[Figure 4]}

In the second group, in contrast to the first group, some bacteria proliferated and became more abundant with salinity build-up in the bioreactor. Based on their responses to the elevated salinity, these bacteria could be classified as halophilic. In total, nine halotolerant or halophilic genera with relative abundance above $0.6 \%$ were identified in this study (Figure 5A). As a notable example, the relative abundance of the genus Methylibium, belonging to the family Comamonadaceae, increased from approximately 3.7 to $14.9 \%$ as the mixed liquor conductivity increased from nearly 0.4 to $13.3 \mathrm{mS} / \mathrm{cm}$ during OMBR operation.

\section{[Figure 5]}


In the third group, an initial increase and then a gradual decrease in the relative abundance of some halotolerant bacteria was observed (Figure 5B). As a notable example, the relative abundance of an uncultured genus affiliated with the family Cytophagaceae increased from nearly 13.1 to $45.5 \%$ when the mixed liquor conductivity increased up to approximately 11 $\mathrm{mS} / \mathrm{cm}$, but then decreased to $32.6 \%$ as the mixed liquor conductivity further increased. This result suggests that a salinity threshold exists for these genera, below which the saline condition favored their growth and metabolism in the bioreactor. in the bioreactor during OMBR operation. Salinity increase in the bioreactor favored the bioreactor significantly reduced the relative abundance of the genus Nitrospira belonged to the

be effectively removed in the bioreactor during OMBR-MD operation as discussed in the proliferation of halotolerant and halophilic microbes to compensate the inhibitory effect on the growth of halophobic bacteria. A typical example is nitrifying bacteria. Salinity build-up in family Nitrospiraceae and the genus A0837 affiliated to the family Nitrosomonadaceae (Figure 4), but increased the relative abundance of an uncultured member of Nitrosomonadaceae (Figure 5). As a result, despite the sensitivity of nitrifying bacteria to the saline condition, ${ }^{11} \mathrm{NH}_{4}{ }^{+}$could following section. Thus, this is the first set of results to demonstrate the potential of an indigenous bacterial community to acclimatize to salinity build-up to maintain a stable biological treatment in OMBR-MD operation.

Contaminant Removal by OMBR-MD. Both organic matter and nutrients were effectively removed by the OMBR-MD hybrid system (Figures 6 and 7), due to the complementarity of biological treatment and two high rejection membrane processes. Effective biological treatment resulted in negligible TOC and $\mathrm{NH}_{4}{ }^{+}$in the bioreactor (Figure 6A\&B). However, TN accumulated considerably in the bioreactor (Figure 6C), because there was no denitrification under aerobic conditions. Some nitrogen species also accumulated in the draw solution since they could pass through the FO but not the MD membrane. $\mathrm{PO}_{4}{ }^{3-}$ was highly rejected by the FO membrane due to its relatively large hydrated radius and negative charge. As a result, there is a notable accumulation of $\mathrm{PO}_{4}{ }^{3-}$ in the bioreactor (Figure 6D). The observed accumulation of $\mathrm{PO}_{4}{ }^{3-}$ presents a good opportunity for phosphorus recovery, for example, by intermittent microfiltration extraction and subsequent chemical precipitation. ${ }^{16}$ 

investigated in this study (Figure 7). Results in Figure 7 also demonstrate that biodegradation was the dominating removal mechanism for these TrOCs. Of the 30 TrOCs, all hydrophobic compounds with $\log D>3.2$ could be effectively removed in the bioreactor (Figure 7). It has been well established that hydrophobic TrOCs could be readily removed by activated sludge because of their adsorption onto biomass for subsequent biodegradation. ${ }^{42}$ As a result, the contribution of the FO rejection to the overall removal efficiency of these hydrophobic compounds in the OMBR-MD hybrid system was insignificant (less than 5\%).

\section{[Figure 7]}

Despite their varying removal in the bioreactor, biodegradation was also the most prevalent removal mechanism of all hydrophilic TrOCs $(\log D<3.2)$ (Figure 7$)$. Such a variation in biological removal could be attributed to the intrinsic biodegradability of these hydrophilic compounds. TrOCs possessing strong electron donating functional groups (e.g., amine and hydroxyl) in the molecular structure are more amendable to electrophilic attack by oxygenase secreted from aerobic bacteria; thus, they are readily biodegradable. ${ }^{42,}{ }^{43}$ In this study, these TrOCs include salicylic acid, ketoprofen, naproxen, metronidazole, ibuprofen, gemfibrozil, propoxur, pentachlorophenol, DEET, and estriol, which achieved removal exceeding $90 \%$ in the bioreactor (Figure 7).

By contrast, TrOCs possessing electron-withdrawing functional groups (e.g., chloro, amide, and nitro) in the molecular structure are persistent to biodegradation, since these functional groups can reduce electrons required for their oxidative catabolism. ${ }^{42}$ In this study, these TrOCs include clofibric acid, fenoprop, primidone, diclofenac, carbamazepine, and atrazine (Figure 7). In fact, the removal of these persistent TrOCs by conventional MBR has been reported to be negligible. ${ }^{42,44-46}$ For example, the removal of carbamazepine in the bioreactor was more than $48 \%$ in this study, while that in conventional MBR was only in the range of $0-14 \% .^{42,45,46}$ Such notable removal deviation was also observed for atrazine, diclofenac, and primidone, with removal efficiency less than $40 \%$ in conventional $\mathrm{MBR},{ }^{42,45,46}$ compared to more than $60 \%$ in the bioreactor in this study. Despite their persistency, due to their extended retention in the bioreactor, biodegradation was still the most prevalent removal mechanism of these hydrophilic TrOCs in OMBR-MD (Figure 7). 
The complementarity between the FO process and biodegradation in OMBR for effective TrOC removal is clearly evidenced in Figure 7. As discussed above, all hydrophobic TrOCs could be biologically removed by more than $90 \%$. Although some hydrophilic TrOCs, such as carbamazepine and atrazine, were recalcitrant to biodegradation, they were well rejected by the FO membrane (Figure S7, SI). As a result, all 30 TrOCs investigated in this study were removed by more than $90 \%$ in OMBR. Thus, the role of MD was restricted mostly to draw solution recovery in the OMBR-MD hybrid system. The contribution of MD toward the overall removal efficiency of TrOCs in the hybrid system was less than $10 \%$ in all cases (Figure 7).

Implications. In this study, continuous operation of an OMBR-MD hybrid system using inexpensive and readily available seawater as the draw solution was demonstrated. The proposed

* (L.D.N.) Phone: +61 24221 4590; fax: + 6124221 3238; email: longn@uow.edu.au.

\section{Notes}

361 The authors declare no competing financial interest.

\section{ACKNOWLEDGMENTS}

This research was supported under the Australian Research Council's Discovery Project funding scheme (Project DP140103864) and National Natural Science Foundation of China (Project 
Supplementary Information. TrOC removals by the bioreactor, OMBR, and the OMBR-

MD hybrid system (Section S1); Key physicochemical properties of the synthetic wastewater and seawater draw solution (Table S1); Key properties of the FO and MD membranes used in this study (Table S2); Physicochemical properties of the 30 TrOCs investigated in this study (Table S3); Photograph of the OMBR-MD hybrid system used for simultaneous wastewater reuse and seawater desalination (Figure S1); Water production of OMBR and MD during OMBR-MD operation (Figure S2); Scanning electron microscopy (SEM) micrographs and with energy dispersive spectroscopy (EDS) spectra of the (A) active layer of the FO membrane, (B) supporting layer of the FO membrane, and (C) MD membrane at the conclusion of OMBR-MD operation (Figure S3), Excitation-emission-intensity matrix (EEM) based on the fluorescence intensity of the seawater draw solution during OMBR-MD operation (Figure S4), Principal coordinate analysis (PCoA) and hierarchical clustering based on the unweighted UniFrac metric (Figure S5), Relative abundance of dominant bacterial phyla (with abundance above $0.5 \%$ ) in the bioreactor during OMBR-MD operation (Figure S6), Rejection of TrOCs by the FO membrane during OMBR-MD operation (Figure S7).

\section{REFERENCES}

1. Shannon, M. A.; Bohn, P. W.; Elimelech, M., Science and technology for water purification in the coming decades. Nature, 2008, 452, 301-310.

2. Lafforgue, M.; Lenouvel, V., Closing the urban water loop: Lessons from Singapore and Windhoek. Environ. Sci.: Water Res. Technol., 2015, 1 (5), 622-631.

3. Elimelech, M., The global challenge for adequate and safe water. J. Water Supply Res. Technol. AQUA, 2006, 55 (1), 3-10.

4. Achilli, A.; Cath, T. Y.; Marchand, E. A.; Childress, A. E., The forward osmosis membrane bioreactor: A low fouling alternative to MBR processes. Desalination, 2009, 239 (1), 10-21.

5. Cornelissen, E. R.; Harmsen, D.; Beerendonk, E. F.; Qin, J. J.; Oo, H.; De Korte, K. F.; Kappelhof, J. W. M. N., The innovative osmotic membrane bioreactor (OMBR) for reuse of wastewater. Water Sci. Technol., 2011, 63 (8), 1557-1565.

6. Nguyen, N. C.; Chen, S. S.; Nguyen, H. T.; Ray, S. S.; Ngo, H. H.; Guo, W.; Lin, P. H., Innovative sponge-based moving bed-osmotic membrane bioreactor hybrid system using a new class of draw solution for municipal wastewater treatment. Water Res., 2016, 91, 305313.

7. Chen, L.; Gu, Y.; Cao, C.; Zhang, J.; Ng, J. W.; Tang, C., Performance of a submerged anaerobic membrane bioreactor with forward osmosis membrane for low-strength wastewater treatment. Water Res., 2014, 50, 114-123. 
8. Wang, X.; Chang, V. W. C.; Tang, C. Y., Osmotic membrane bioreactor (OMBR) technology for wastewater treatment and reclamation: Advances, challenges, and prospects for the future. J. Membr. Sci., 2016, 504, 113-132.

9. Holloway, R. W.; Achilli, A.; Cath, T. Y., The osmotic membrane bioreactor: A critical review. Environ. Sci.: Water Res. Technol., 2015, 1 (5), 581-605.

10. Luo, W.; Phan, H. V.; Xie, M.; Hai, F. I.; Price, W. E.; Elimelech, M.; Nghiem, L. D., Osmotic versus conventional membrane bioreactors integrated with reverse osmosis for water reuse: Biological stability, membrane fouling, and contaminant removal. Water Res., 2017, 109, 122-134.

11. Qiu, G. L.; Ting, Y. P., Osmotic membrane bioreactor for wastewater treatment and the effect of salt accumulation on system performance and microbial community dynamics. Bioresour. Technol., 2013, 150, 287-297.

12. Lay, W. C. L.; Liu, Y.; Fane, A. G., Impacts of salinity on the performance of high retention membrane bioreactors for water reclamation: A review. Water Res., 2010, 44 (1), 21-40.

13. Luo, W.; Phan, H. V.; Hai, F. I.; Price, W. E.; Guo, W.; Ngo, H. H.; Yamamoto, K.; Nghiem, L. D., Effects of salinity build-up on the performance and bacterial community structure of a membrane bioreactor. Bioresour. Technol., 2016, 200, 305-310.

14. Holloway, R. W.; Regnery, J.; Nghiem, L. D.; Cath, T. Y., Removal of trace organic chemicals and performance of a novel hybrid ultrafiltration-osmotic membrane bioreactor. Environ. Sci. Technol., 2014, 48 (18), 10859-10868.

15. Holloway, R. W.; Wait, A. S.; Da Silva, A. F.; Herron, J.; Schutter, M. D.; Lampi, K.; Cath, T. Y., Long-term pilot scale investigation of novel hybrid ultrafiltration-osmotic membrane bioreactors. Desalination, 2015, 363, 64-74.

16. Luo, W.; Hai, F. I.; Price, W. E.; Guo, W.; Ngo, H. H.; Yamamoto, K.; Nghiem, L. D., Phosphorus and water recovery by a novel osmotic membrane bioreactor-reverse osmosis system. Bioresour. Technol., 2016, 200, 297-304.

17. Nghiem, L. D.; Cath, T., A scaling mitigation approach during direct contact membrane distillation. Sep. Purif. Technol., 2011, 80, 315-322.

18. Shaffer, D. L.; Arias Chavez, L. H.; Ben-Sasson, M.; Romero-Vargas Castrillón, S.; Yip, N. Y.; Elimelech, M., Desalination and reuse of high-salinity shale gas produced water: Drivers, technologies, and future directions. Environ. Sci. Technol., 2013, 47 (17), 95699583.

19. Nguyen, N. C.; Chen, S. S.; Thi Nguyen, H.; Chen, Y. H.; Hao Ngo, H.; Guo, W.; Sinha Ray, S.; Chang, H. M.; Huy Le, Q., Applicability of an integrated moving sponge biocarrier-osmotic membrane bioreactor MD system for saline wastewater treatment using highly salt-tolerant microorganisms. Sep. Purif. Technol. , 2017, In Press (DOI: http://dx.doi.org/10.1016/j.seppur.2017.01.011).

20. Nguyen, N. C.; Nguyen, H. T.; Chen, S. S.; Ngo, H. H.; Guo, W.; Chan, W. H.; Ray, S. S.; Li, C. W.; Hsu, H. T., A novel osmosis membrane bioreactor-membrane distillation hybrid system for wastewater treatment and reuse. Bioresour. Technol., 2016, 209, 8-15. 
21. Shahzad, M. A.; Khan, S. J.; Siddique, M. S., Draw solution recovery using direct contact membrane distillation (DCMD) from osmotic membrane bioreactor (Os-MBR). J. Water Process Eng., 2017, In Press (DOI: https://doi.org/10.1016/j.jwpe.2017.08.022).

22. Shaffer, D. L.; Yip, N. Y.; Gilron, J.; Elimelech, M., Seawater desalination for agriculture by integrated forward and reverse osmosis: Improved product water quality for potentially less energy. J. Membr. Sci., 2012, 415-416, 1-8.

23. Zaviska, F.; Chun, Y.; Heran, M.; Zou, L., Using FO as pre-treatment of RO for high scaling potential brackish water: Energy and performance optimisation. J. Membr. Sci., 2015, 492, 430-438.

24. Hancock, N. T.; Xu, P.; Roby, M. J.; Gomez, J. D.; Cath, T. Y., Towards direct potable reuse with forward osmosis: Technical assessment of long-term process performance at the pilot scale. J. Membr. Sci., 2013, 445, 34-46.

25. Cath, T. Y.; Hancock, N. T.; Lundin, C. D.; Hoppe-Jones, C.; Drewes, J. E., A multi-barrier osmotic dilution process for simultaneous desalination and purification of impaired water. $J$. Membr. Sci., 2010, 362 (1-2), 417-426.

26. Luo, Y. L.; Guo, W. S.; Ngo, H. H.; Nghiem, L. D.; Hai, F. I.; Zhang, J.; Liang, S.; Wang, X. C. C., A review on the occurrence of micropollutants in the aquatic environment and their fate and removal during wastewater treatment. Sci. Total Environ., 2014, 473, 619641.

27. Alturki, A. A.; McDonald, J. A.; Khan, S. J.; Price, W. E.; Nghiem, L. D.; Elimelech, M., Removal of trace organic contaminants by the forward osmosis process. Sep. Purif. Technol., 2013, 103, 258-266.

28. Hai, F. I.; Tessmer, K.; Nguyen, L. N.; Kang, J.; Price, W. E.; Nghiem, L. D., Removal of micropollutants by membrane bioreactor under temperature variation. J. Membr. Sci., 2011, 383 (1), 144-151.

29. Zhang, J. J.; Kobert, K.; Flouri, T.; Stamatakis, A., PEAR: a fast and accurate Illumina Paired-End reAd mergeR. Bioinformatics, 2014, 30, 614-620.

30. Caporaso, J. G.; Kuczynski, J.; Stombaugh, J.; Bittinger, K.; Bushman, F. D.; Costello, E. K.; Fierer, N.; Peña, A. G.; Goodrich, J. K.; Gordon, J. I.; Huttley, G. A.; Kelley, S. T.; Knights, D.; Koenig, J. E.; Ley, R. E.; Lozupone, C. A.; McDonald, D.; Muegge, B. D.; Pirrung, M.; Reeder, J.; Sevinsky, J. R.; Turnbaugh, P. J.; Walters, W. A.; Widmann, J.; Yatsunenko, T.; Zaneveld, J.; Knight, R., QIIME allows analysis of high-throughput community sequencing data. Nat. Methods, 2010, 7 (5), 335-336.

31. Edgar, R. C., UPARSE: Highly accurate OTU sequences from microbial amplicon reads. Nat. Methods, 2013, 10 (10), 996-998.

32. Mcilroy, S. J.; Saunders, A. M.; Albertsen, M.; Nierychlo, M.; Mcilroy, B.; Hansen, A. A.; Karst, S. M.; Nielsen, J. L.; Nielsen, P. H., MiDAS: the field guide to the microbes of activated sludge. Database, 2015, 2015, 1-8.

33. Hughes, J. B.; Hellmann, J. J.; Ricketts, T. H.; Bohannan, B. J. M., Counting the uncountable: statistical approaches to estimating microbial diversity. Appl. Environ. Microbiol., 2001, 67 (10), 4399-4406. 
34. Shannon, C. E., A Mathematical Theory of Communication. SIGMOBILE Mob. Comput. Commun. Rev., 2001, 5 (1), 3-55.

35. Faith, D. P., Conservation evaluation and phylogenetic diversity. Biol. Conserv., 1992, 61 (1), 1-10.

36. Hou, D.; Lu, L.; Ren, Z. J., Microbial fuel cells and osmotic membrane bioreactors have mutual benefits for wastewater treatment and energy production. Water Res., 2016, 98, 183189.

37. Xiao, D.; Tang, C. Y.; Zhang, J.; Lay, W. C. L.; Wang, R.; Fane, A. G., Modeling salt accumulation in osmotic membrane bioreactors: Implications for FO membrane selection and system operation. J. Membr. Sci., 2011, 366 (1-2), 314-324.

38. Luo, W.; Hai, F. I.; Price, W. E.; Nghiem, L. D., Water extraction from mixed liquor of an aerobic bioreactor by forward osmosis: Membrane fouling and biomass characteristics assessment. Sep. Purif. Technol., 2015, 145 (0), 56-62.

39. Boo, C.; Elimelech, M.; Hong, S., Fouling control in a forward osmosis process integrating seawater desalination and wastewater reclamation. J. Membr. Sci., 2013, 444, 148-156.

40. Tijing, L. D.; Woo, Y. C.; Choi, J.-S.; Lee, S.; Kim, S.-H.; Shon, H. K., Fouling and its control in membrane distillation-A review. J. Membr. Sci., 2015, 475, 215-244.

41. Crump, B. C.; Hopkinson, C. S.; Sogin, M. L.; Hobbie, J. E., Microbial Biogeography along an Estuarine Salinity Gradient: Combined Influences of Bacterial Growth and Residence Time. Appl. Environ. Microbiol. , 2004, 70 (3), 1494-1505.

42. Tadkaew, N.; Hai, F. I.; McDonald, J. A.; Khan, S. J.; Nghiem, L. D., Removal of trace organics by MBR treatment: The role of molecular properties. Water Res., 2011, 45 (8), 2439-2451.

43. Knackmuss, H. J., Basic knowledge and perspectives of bioelimination of xenobiotic compounds. J. Biotechnol., 1996, 513, 287-295.

44. Tadkaew, N.; Sivakumar, M.; Khan, S. J.; McDonald, J. A.; Nghiem, L. D., Effect of mixed liquor $\mathrm{pH}$ on the removal of trace organic contaminants in a membrane bioreactor. Bioresour. Technol., 2010, 101, 1494-1500.

45. Bernhard, M.; Müller, J.; Knepper, T. P., Biodegradation of persistent polar pollutants in wastewater: Comparison of an optimised lab-scale membrane bioreactor and activated sludge treatment. Water Res., 2006, 40 (18), 3419-3428.

46. Wijekoon, K. C.; Hai, F. I.; Kang, J.; Price, W. E.; Guo, W.; Ngo, H. H.; Nghiem, L. D., The fate of pharmaceuticals, steroid hormones, phytoestrogens, UV-filters and pesticides during MBR treatment. Bioresour. Technol., 2013, 144, 247-254. 


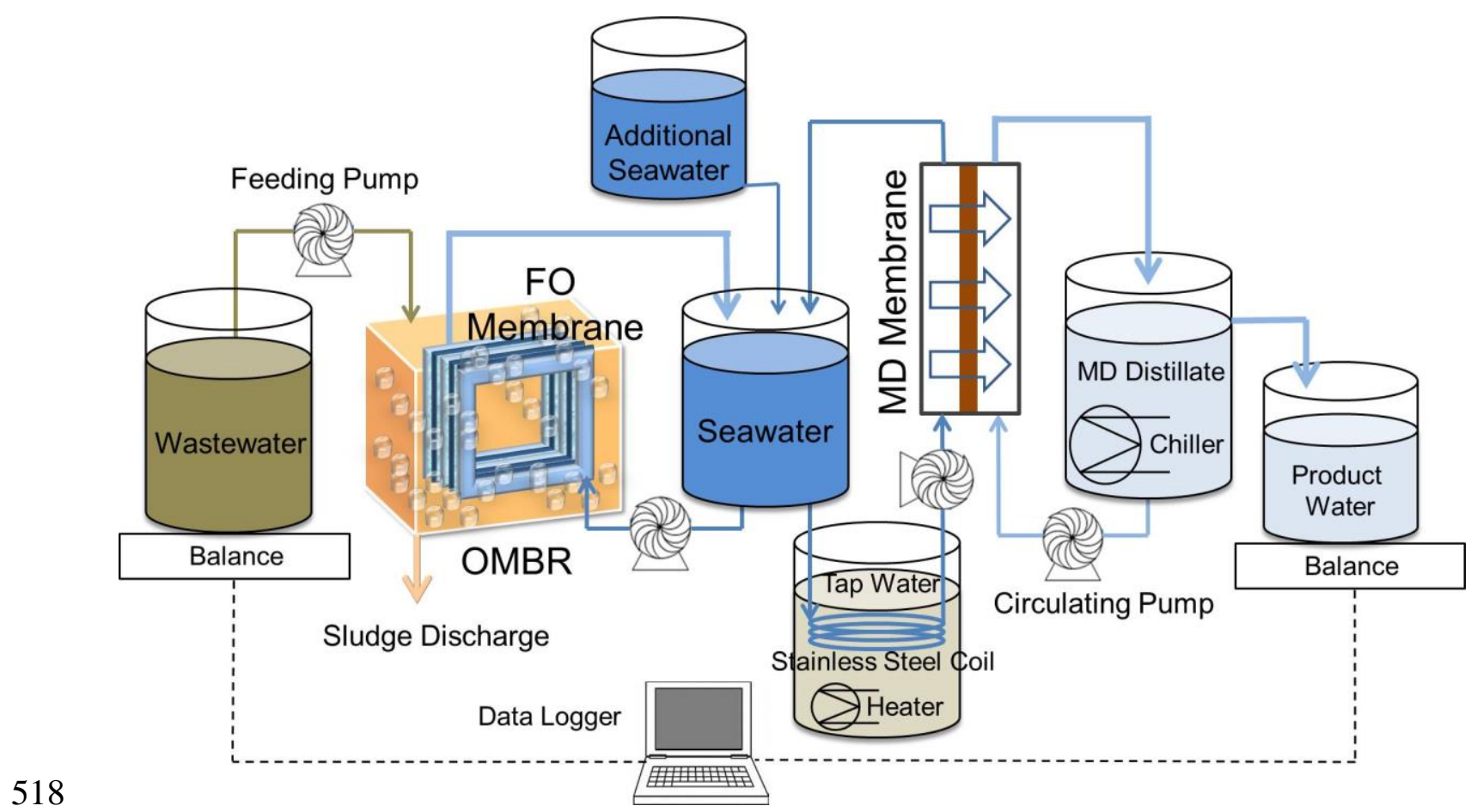

519 Figure 1: Schematic diagram of the OMBR-MD hybrid system for simultaneous wastewater 520 reuse and seawater desalination. 

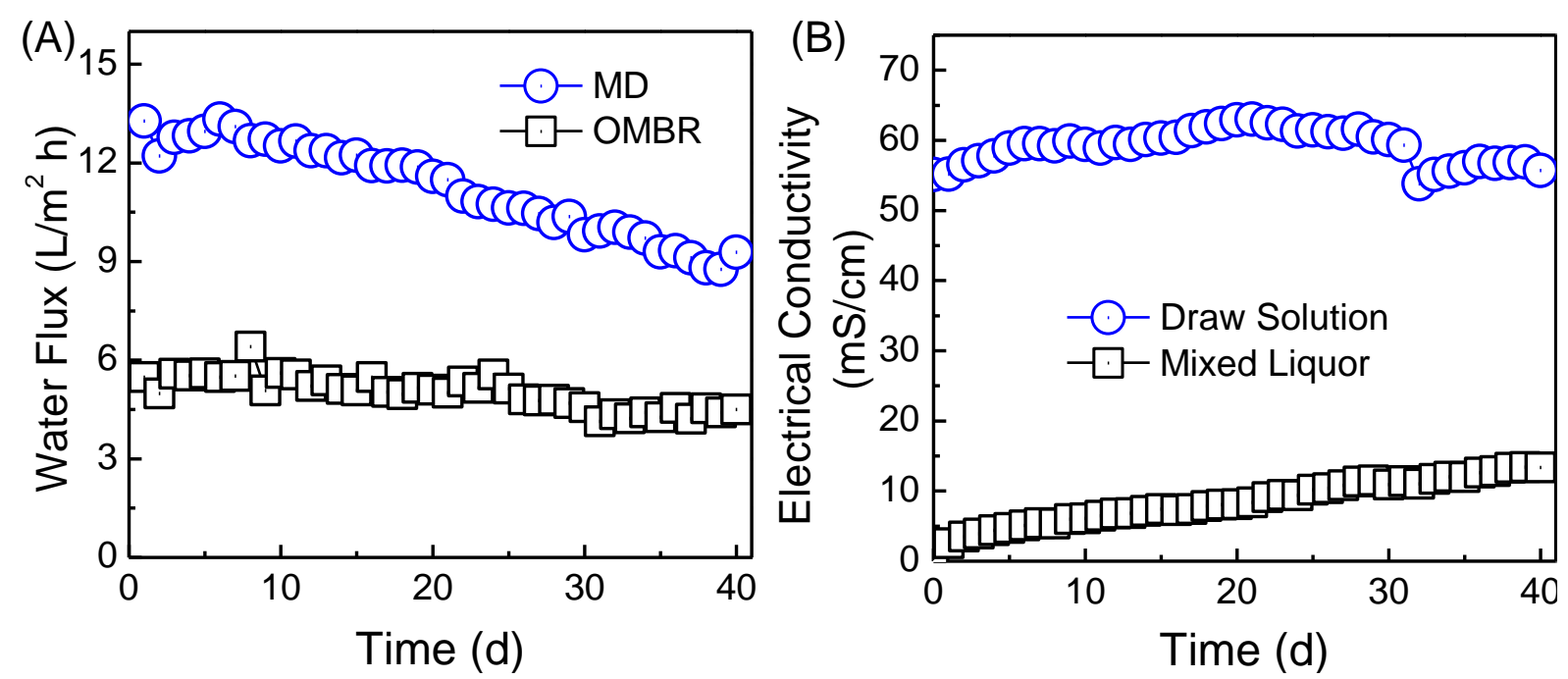

522 Figure 2: (A) Water flux of OMBR and MD. (B) Electrical conductivity of the mixed liquor

523 and seawater draw solution during OMBR-MD operation. Experimental conditions: DO = 5

$524 \mathrm{mg} / \mathrm{L}$, initial MLSS $=6 \mathrm{~g} / \mathrm{L}, \mathrm{SRT}=20 \mathrm{~d}$, bioreactor temperature $=25 \pm 1{ }^{\circ} \mathrm{C}$, draw solution

525 cross-flow velocity $=2.8 \mathrm{~cm} / \mathrm{s}$, draw solution temperature $=35 \pm 1{ }^{\circ} \mathrm{C}$, $\mathrm{MD}$ feed and distillate

526 cross-flow velocity $=8.8 \mathrm{~cm} / \mathrm{s}$, MD feed solution temperature $=40 \pm 1{ }^{\circ} \mathrm{C}$, and MD distillate

527 temperature $=20 \pm 1{ }^{\circ} \mathrm{C}$. Seawater after microfiltration pretreatment was used as the draw

528 solution. Draw solution was replenished continuously to maintain a working volume at $10 \mathrm{~L}$. 

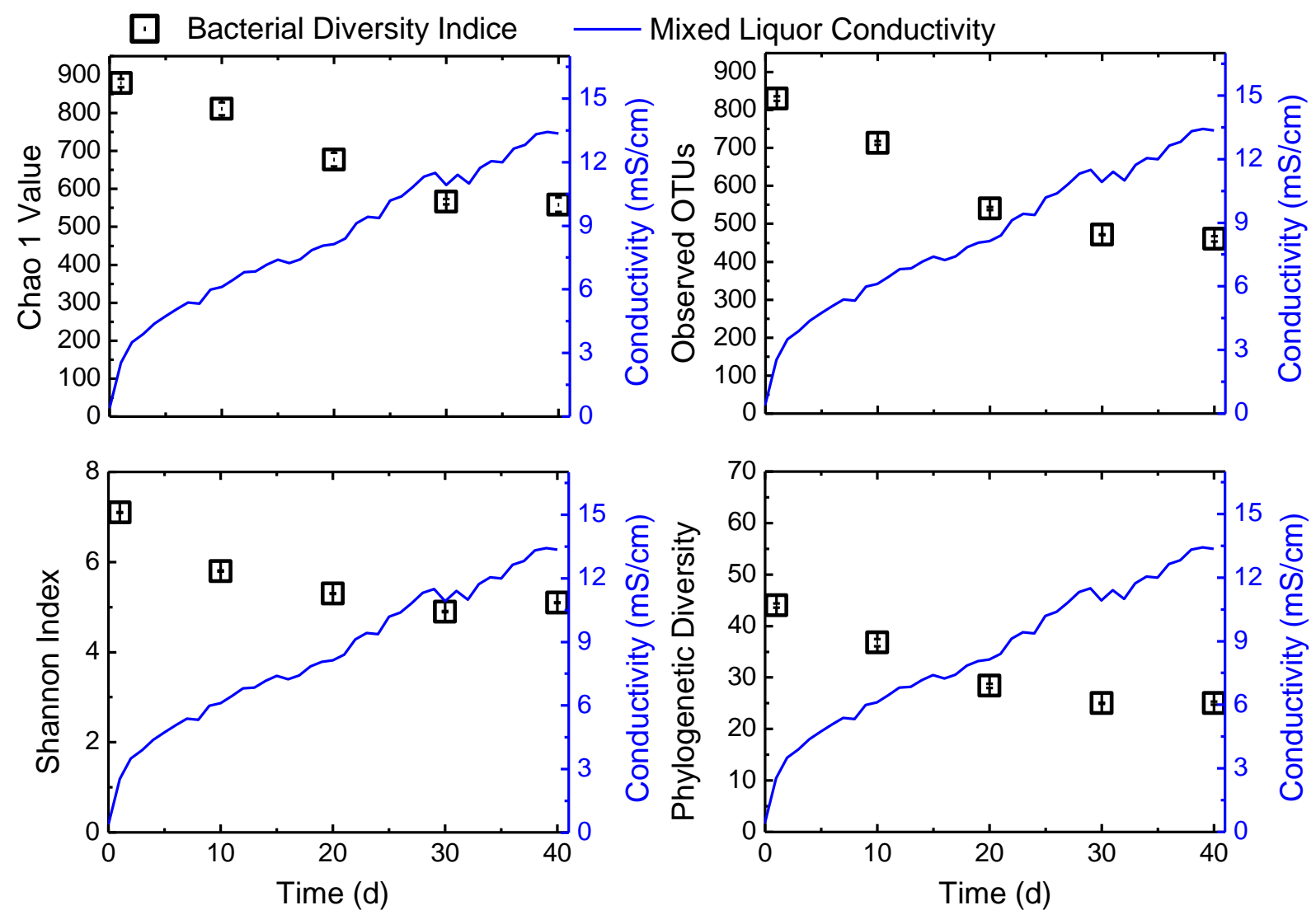

531 Figure 3: The $\alpha$-diversity indices (i.e., Chao 1 value, Observed OTUs, Shannon index, and

532 phylogenetic diversity) of mixed liquor samples collected during OMBR-MD operation.

533 Diversity indices were estimated at the minimum sequencing depth of all samples (i.e.,

53443,000 sequences per sample). Error bars represent the standard deviation from 10 repetitions

535 of each sample. Coverage of all samples was more than $99.5 \%$. Experimental conditions are as described in Figure 2. 

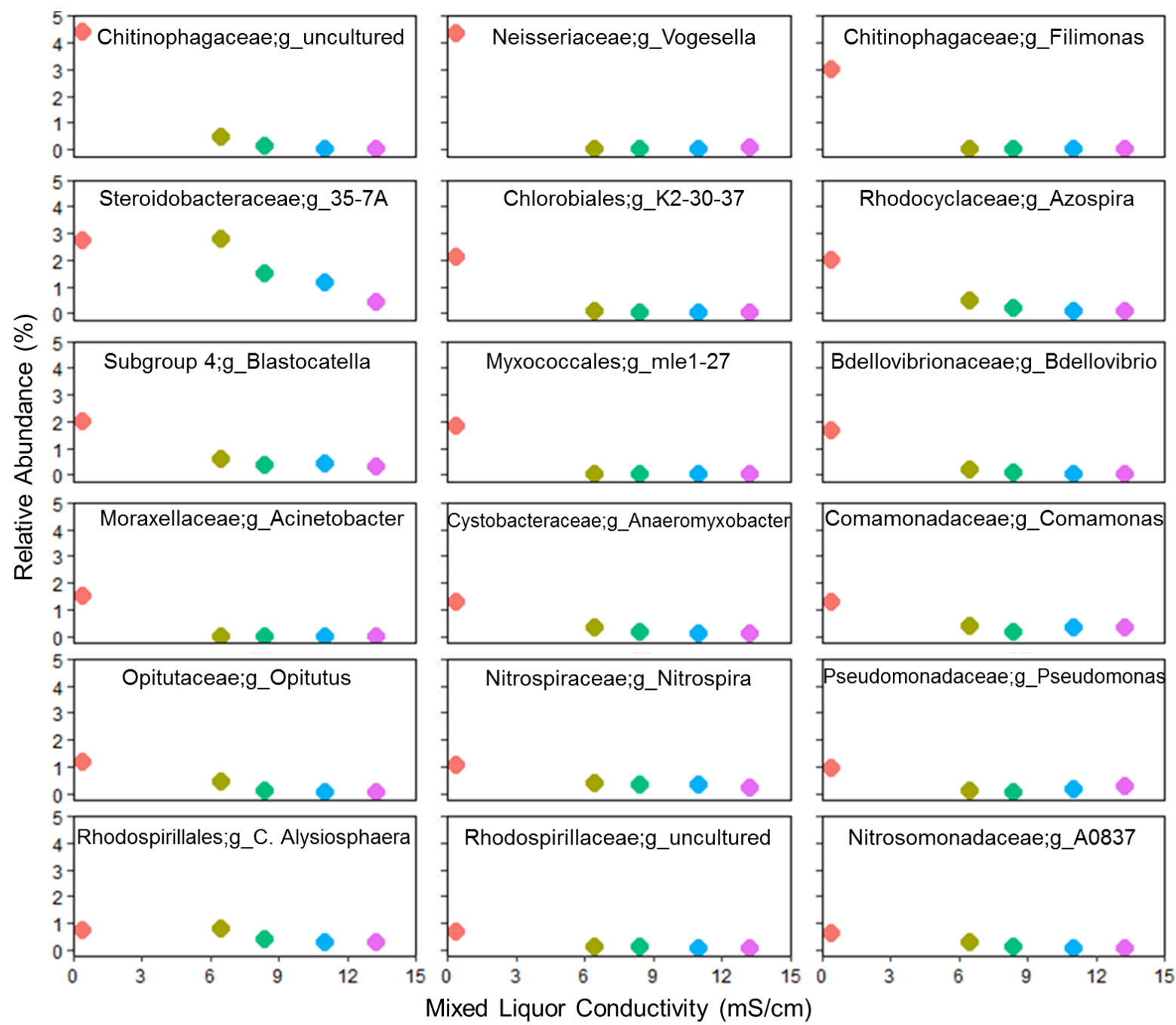

Mixed Liquor Conductivity $(\mathrm{mS} / \mathrm{cm})$

538 Figure 4: Relative abundance of 18 major bacterial genera (with relative abundance $>0.6 \%$ )

539 whose growth was inhibited with salinity build-up in the bioreactor (indicated by the mixed

540 liquor conductivity) during OMBR-MD operation. Experimental conditions are as described in Figure 2. 
(A)

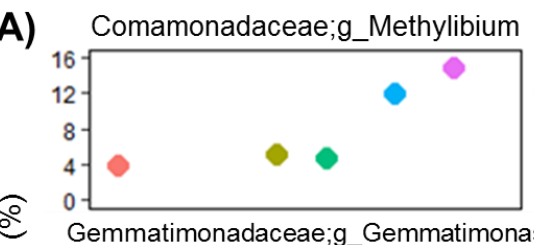

Xanthomonadaceae;g_Dokdonella

Caulobacteraceae;g_Brevundimonas
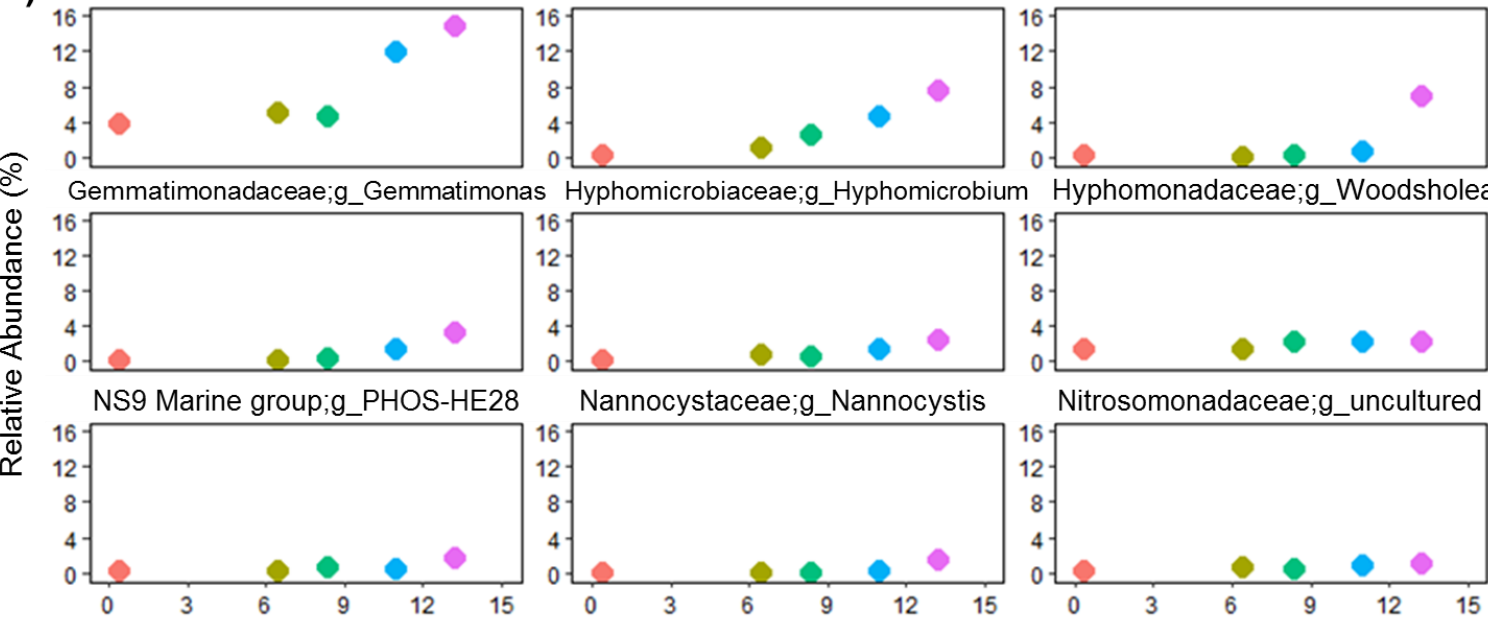

Syphomicrobiaceae;g_Hyphomicrobium Hyphomonadaceae;g_Woodsholea
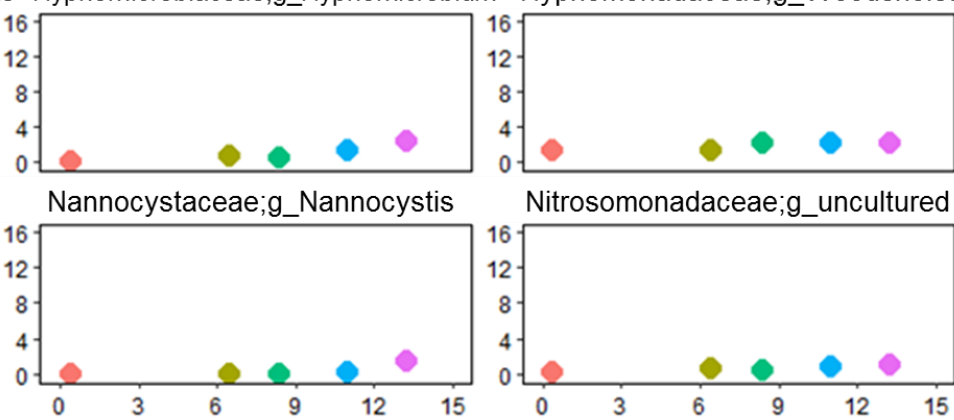

Nitrosomonadaceae;g_uncultured

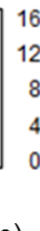

Mixed Liquor Conductivity ( $\mathrm{mS} / \mathrm{cm})$

(B) Cytophagaceae;g_uncultured
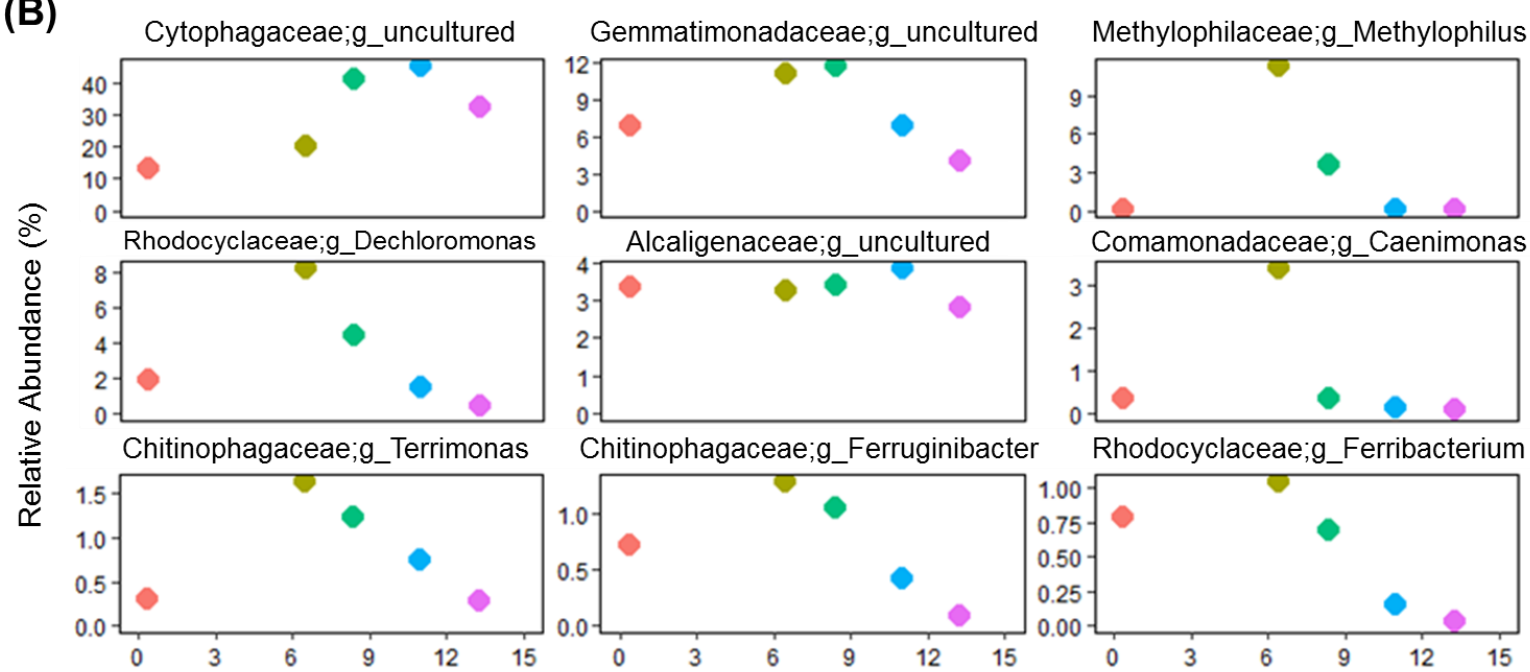

Comamonadaceae;g Caenimonas
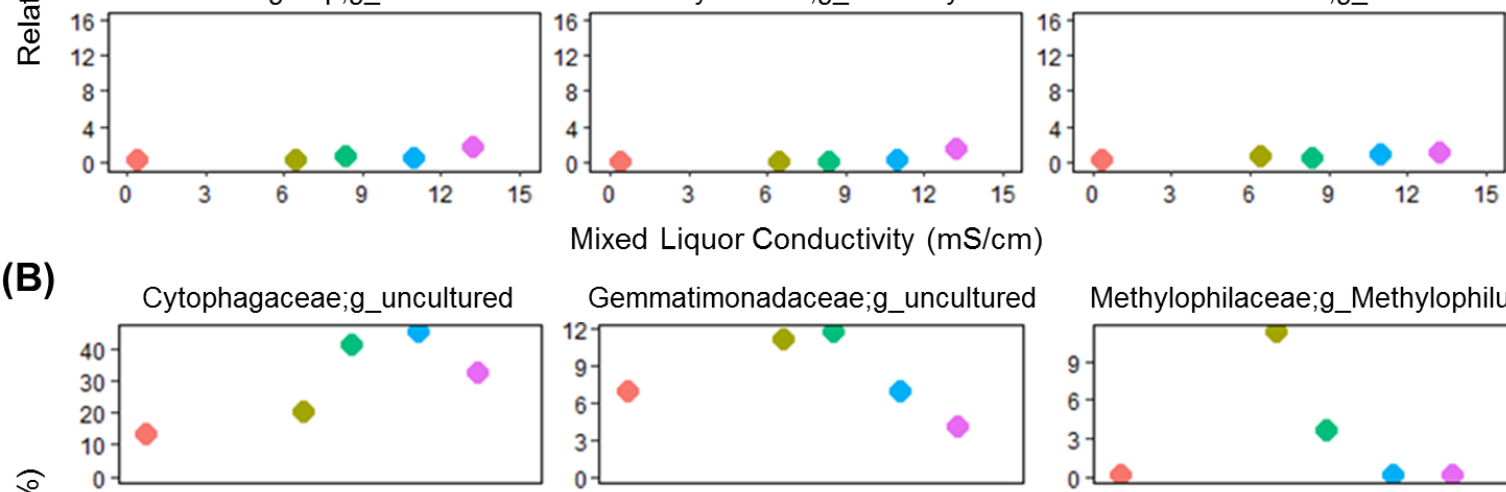

Chitinophagaceae;g_Ferruginibacter Rhodocyclaceae;g_Ferribacterium
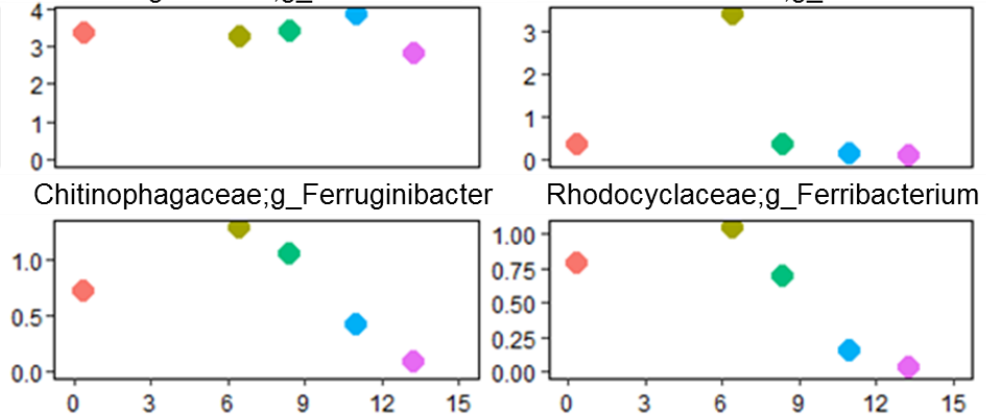

Mixed Liquor Conductivity (mS/cm)

543 Figure 5: Relative abundance of major bacterial genera (with relative abundance $>0.6 \%$ )

544 that proliferated (A) continuously and (B) only to some extent with salinity build-up in the

545 bioreactor (indicated by the mixed liquor conductivity) during OMBR-MD operation.

546 Experimental conditions are as described in Figure 2. 

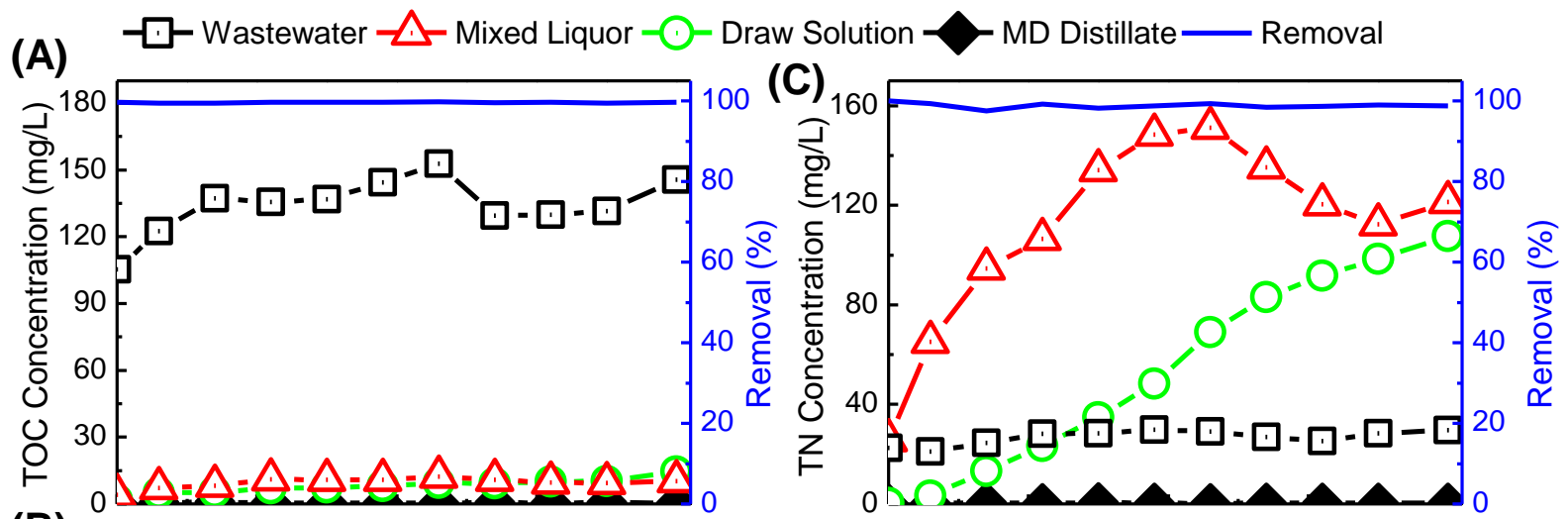

(B)

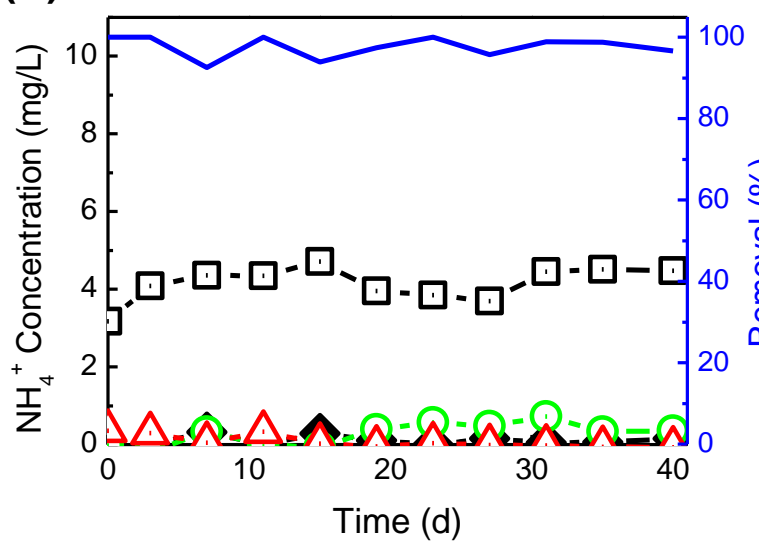

(D)

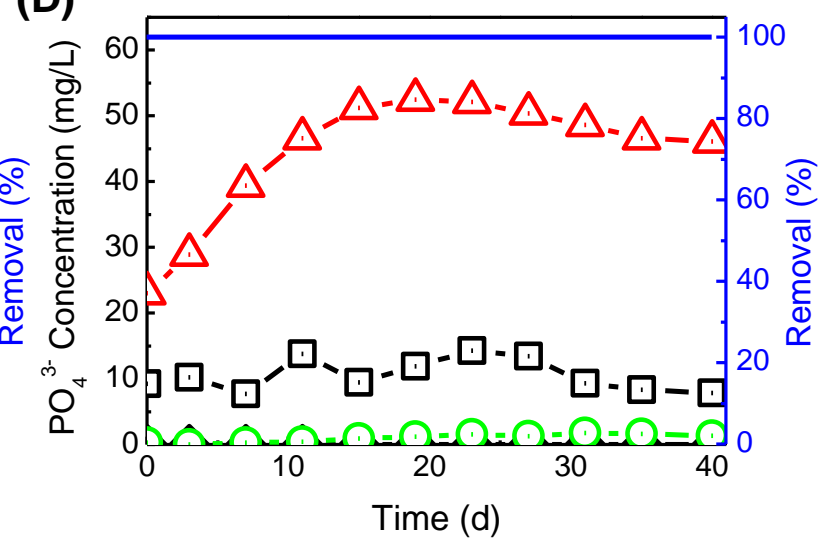

549 Figure 6: Distribution of (A) TOC, (B) $\mathrm{NH}_{4}{ }^{+}$, (C) $\mathrm{TN}$, and (D) $\mathrm{PO}_{4}{ }^{3-}$ as well as their overall

550 removal in the OMBR-MD hybrid system. Experimental conditions are as summarized in

551 Figure 2. 


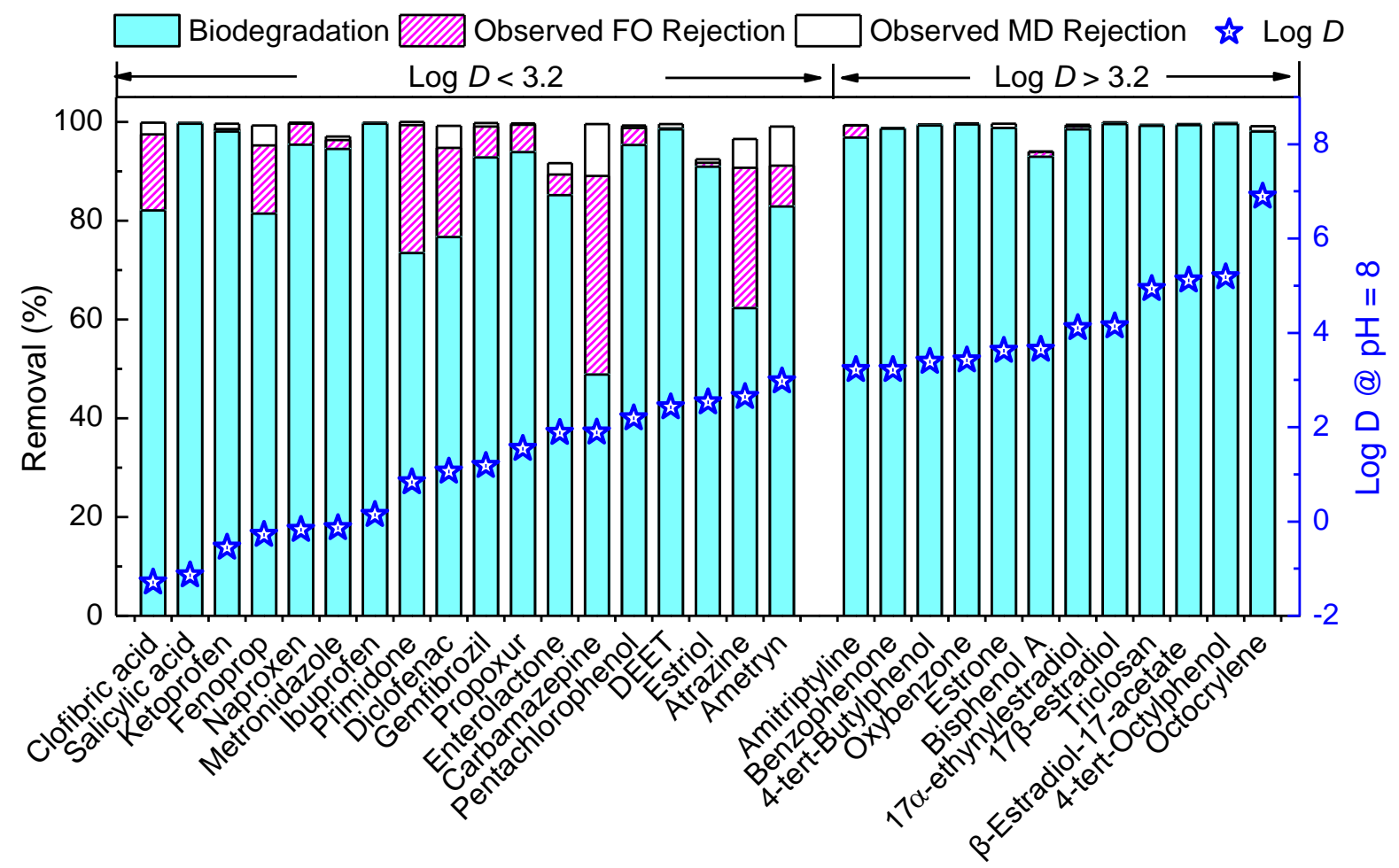

554 Figure 7: Removal of TrOCs by different units (i.e., bioreactor, FO membrane, and MD

555 membrane) of the OMBR-MD hybrid system. Average removal data obtained from five

556 measurements are shown, with standard deviation in the range of 0.1 to $30 \%$. TrOCs are

557 ordered according to their effective octanol-water partition coefficient (i.e., $\log D$ ) at

558 solution $\mathrm{pH}$ 8. Observed FO rejection shows the removal difference between bioreactor and

559 OMBR, while observed MD rejection is the removal difference between OMBR and OMBR-

560 MD. Experimental conditions are as described in Figure 2. 